\title{
O Chavismo implantou o socialismo na Venezuela? um estudo de caso sobre como conceituar economias contemporâneas
}

Lucas Lemos Walmrath ${ }^{I}$

Wallace de Moraes ${ }^{I I}$

\begin{abstract}
Resumo: Tem sido muito comum jornalistas e cientistas políticos afirmarem que a Venezuela, sob os governos Chávez, era socialista, assumindo acriticamente o conceito de Socialismo do Século XXI. Para problematizar a questão, realizamos a seguinte pesquisa: 1) buscamos por sínteses dos conceitos de socialismo e capitalismo em dicionários especializados de Economia e Ciência Política; 2) resgatamos as concepções de socialismo definidas por Marx e Engels e pela literatura libertária; 3) trouxemos dados econômicos sobre empresas públicas e privadas e a respectiva concentração de sua mão de obra na Venezuela sob a Era Chávez. De acordo com os quais, concluímos que a Venezuela não pode ser enquadrada como uma economia socialista, pois os principais postulados do capitalismo ainda predominam no país caribenho. Por fim, apresentamos o conceito de plutocracia social-democrata de las calles como melhor forma de representar a economia venezuelana sob a governança política de Hugo Chávez.
\end{abstract}

Palavras-chave: Venezuela; Chavismo; Socialismo; capitalismo; plutocracia socialdemocrata de las calles.

\section{Does Venezuela have a socialist economy? A case study on how to conceptualize contemporary economies}

Abstract: It has been commonplace for journalists and political scientists to claim that Venezuela, under the Chavez administrations, was socialist by assuming - not carefully - the concept of 21 st Century Socialism. In order to challenge this position, we conducted the following research: 1) we searched for syntheses of the concepts of socialism and capitalism in specialized dictionaries of Economics and Political Science; 2) we rescue the concepts of socialism as defined by Marx and Engels and by the socialist libertarian literature; 3) we brought economic data on public and private companies and the respective concentration of their workforce in Venezuela under the Chávez Era. Considering both data and the concepts, we conclude that Venezuela cannot be classified as a socialist economy, since the main postulates of capitalism still predominate in the Caribbean country. Finally, we present the concept of social-democratic plutocracy of las calles as the best way to represent the Venezuelan economy under Hugo Chávez's political governance.

Key words: Venezuela; Chavismo; Socialism; capitalism; social-democratic plutocracy of las calles.

Artigo recebido em 15/10/2019 e aprovado em 27/11/2019. 


\title{
O CHAVISMO IMPLANTOU O SOCIALISMO NA VENEZUELA? UM ESTUDO DE CASO SOBRE COMO CONCEITUAR ECONOMIAS CONTEMPORÂNEAS
}

\author{
LUCAS LEMOS WALMRATH \\ WALLACE DE MORAES
}

\section{INTRODUÇÃO}

A conceituação e classificação de economias, seus regimes políticos, características e particularidades sociais e culturais, sempre despertou o interesse das Ciências Sociais como um todo, em específico de cientistas políticos. Essas conceituações podem - e devem - ser estudadas e conduzidas em diversos âmbitos, posto que se trata de um problema interdisciplinar. No entanto, muitas controvérsias parecem surgir quando acadêmicos de áreas afins tentam construir algum consenso refinado para descrever e entender a realidade de países, seus governos e economias, por meio dos conceitos disponíveis. Afirmamos que parte desses problemas de conceituação podem se dever a dificuldade inerente a empreitada, assim como por definições ambíguas e entendimentos culturais distintos sobre os mesmos conceitos, sem contar, evidentemente, as visões normativas de partidários de distintas vertentes ideológicas.

No contexto latino-americano, um dos países que mais levanta debates acerca de sua natureza política-econômica, seja por populares ou acadêmicos, é a Venezuela. Após a vitória eleitoral de Hugo Chávez em 1998, pode-se dizer que a década de 2000 presenciou uma guinada à centro-esquerda em grande parte da América do Sul. Foi, na verdade, um freio às políticas neoliberais arrojadas implementadas até então no continente. Em uma década marcada pela dissolução da União das Repúblicas Socialistas Soviéticas (URSS, dissolvida em 1991) e pela expectativa ${ }^{\text {III }}$ do triunfo de uma ordem político-econômica espelhada no alicerce e exemplo europeu e estadunidense simbolizada pelo Consenso de Washington ${ }^{\text {IV }}$, ao combinar o sistema capitalista neoliberal com democracias liberais representativas, presidencialistas ou parlamentaristas, Chávez dava o primeiro passo para esta guinada à esquerda, sem dúvida, a mais profunda entre todas as outras experiências, por isso posteriormente classificada como socialista.

Exposto este breve contexto histórico de mudanças em direção a governos desalinhados à direita politicamente, partimos da premissa de que, mesmo sem uma precisa mensuração de quantos entendem a Venezuela como socialista, a mera constatação desta conceituação, por si só, já levanta um problema pertinente a ser investigado. Cabe lembrar que até o atual presidente dos EUA, Donald Trump, se referiu a Venezuela como socialista ${ }^{\mathrm{V}}$, ao criticar o governo de Nicolás Maduro.

O primeiro aspecto a destacar é que cada governança política pode atribuir à sua administração o nome que bem entender. Não discutiremos isso. Não obstante, um cientista social não pode negligenciar a história das ideias políticas, bem como os instrumentos necessários para caracterizar um conjunto de políticas públicas, de acordo com critérios objetivos. Para tanto, nosso caminho metodológico não pode classificar todo e qualquer conceito de socialismo simplesmente como um anátema, como fazem as perspectivas conservadoras e liberais, atribuindo-lhes todos os males da organização societal sob seu nome.

A Era Chávez é majoritariamente interpretada por duas diferentes maneiras. A literatura liberal a classifica como populista, ou como uma ditadura, às vezes até como um amálgama das duas coisas. Os social-democratas no mundo inteiro interpretam o governo Chávez como um grande líder que criou direitos para os pobres na Venezuela. Ambas incorreram em um grande erro: personalizar toda uma governança política. Trata-se da perspectiva da ágora-fobia política ${ }^{\mathrm{VI}}$ que, ao seguir na perspectiva aristocrática, ignora ou desmerece a participação popular e foca todo um governo em uma única pessoa. Ao fazer isso, essas matrizes teóricas mostram todo seu caráter autoritário e centralista. 


\section{O CHAVISMO IMPLANTOU O SOCIALISMO NA VENEZUELA? UM ESTUDO DE CASO SOBRE COMO CONCEITUAR ECONOMIAS CONTEMPORÂNEAS}

\section{LUCAS LEMOS WALMRATH \\ WALLACE DE MORAES}

Nossa análise, amparada tanto na ágora-filia política quanto no histórico das lutas dos governados na Venezuela, aponta para o entendimento do chavismo como resultado delas. Assim, a governança política de Hugo Chávez Frías (1999-2013) foi consequência da força crescente dos movimentos sociais, desde, pelo menos, meados da década de 1980, culminando com a explosão do Caracazo, em 1989. A partir de então, os governados não saíram mais das ruas, tendo aumentado sua intensidade em $1999^{\mathrm{VII}}$, quando ocorreram ocupações de terras e de prédios. O governo Chávez, portanto, foi oriundo das forças dos trabalhadores organizados nas calles, contrários às políticas neoliberais.

Feitas as ressalvas necessárias, propomos uma contribuição para o debate na forma de um estudo de caso, visando debater a alegação de que a Venezuela chavista se configura como um exemplo de Socialismo. O artigo se subdivide nas seguintes seções: Revisão de Literatura, onde revisamos brevemente o debate acadêmico quanto a melhor conceituação da Venezuela sob o Chavismo; Metodologia, onde exporemos a abordagem escolhida para lidar com a questão colocada nesta introdução; Resultados, onde apresentamos os achados dos dados e das leituras conduzidas; por fim, na seção de Discussão discutiremos os resultados encontrados na seção anterior, concluindo o artigo com uma reflexão libertária e crítica.

\section{COMO O MAINSTREAM TEM CLASSIFICADO O GOVERNO CHÁVEZ - BREVE REVISÃO DA LITERATURA}

Nesta seção, apresentamos um breve apanhado da literatura acadêmica sobre o problema levantado. É preciso dizer que, para os intentos desta pesquisa, muitos dos artigos e livros pesquisados não versavam sobre o exato problema a qual nos propomos neste artigo, isto é, de conceituar a economia venezuelana enquanto socialista. Muitos dos estudos a seguir se concentraram em descrever o Chavismo em suas facetas políticas e econômicas. Para Steve Ellner ${ }^{\mathrm{VIII}}$, por exemplo, "A maioria dos analistas políticos coloca os governos de Hugo Chávez (Venezuela), Evo Morales (Bolívia) e Rafael Correa (Equador) na mesma categoria, mas sem identificar suas características comuns". O mesmo autor salienta ${ }^{\mathrm{IX}}$ que "Morales, Chávez e Correa propuseram adaptar o socialismo à realidade concreta da América Latina, numa época em que a sabedoria convencional no Ocidente é de que este modelo está quase morto".

Hawkins ${ }^{\mathrm{X}}$ conceitua politicamente o Chavismo como um fenômeno do populismo, ainda que reminiscente e não idêntico aos modos clássicos do século XX. Schamis ${ }^{\mathrm{XI}}$ entende ser o Chavismo um representante da petro-esquerda: uma versão do século XXI da dominação patrimonial sobre o Estado, composta por uma oratória populista vaga, conjuntamente a objetivos nebulosos em sua suposta direção ao socialismo. No entanto, o autor descarta o conceito de populismo para entender o Chavismo e demais esquerdas latino-americanas contemporâneas $^{\text {XII }}$. Mainwaring ${ }^{\text {XIII }}$ enxerga historicamente a Venezuela migrando da democracia representativa - ou partidocracia - que durara desde 1953, para, em tempos de Chavismo, um regime autoritário, ainda que participatório e competitivo politicamente.

Jorge Lanzaro ${ }^{\mathrm{XIV}}$ estabeleceu três conceitos para classificar os governos latinoamericanos do século XXI: populista, nacional-popular e social-democrata. A alocação em um dos três depende fundamentalmente do respeito/desrespeito aos preceitos macroeconômicos neoclássicos. Isto é, se o governo respeita esses fundamentos e, ainda assim, investe no social com o que sobra, é classificado como social-democrata. Se o modelo não desrespeita os postulados determinados pelos organismos internacionais e seus governantes políticos pertencem a partidos tradicionais, então é classificado de nacionalismo popular. Quando o governo desrespeita os fundamentos da macroeconomia, impondo um controle 


\section{O CHAVISMO IMPLANTOU O SOCIALISMO NA VENEZUELA? UM ESTUDO DE CASO SOBRE COMO CONCEITUAR ECONOMIAS CONTEMPORÂNEAS}

\section{LUCAS LEMOS WALMRATH \\ WALLACE DE MORAES}

sobre o mercado com objetivos redistributivos, sem o devido "cuidado" com o déficit fiscal e os equilíbrios econômicos, é logo classificado como populista. Estes são os principais argumentos para a alocação em um dos conceitos estabelecidos pelo autor. Sob esta lógica, o governo Chávez foi populista.

Pannizza $^{\mathrm{XV}}$ divide as governanças políticas dos anos 2000 na América Latina em socialdemocratas e populistas. Aqueles respeitam os ditames do mercado, têm relações com os sindicatos e são estáveis. Já os populistas, caracterizam-se pelos mesmos princípios ditados por Lanzaro $^{\mathrm{XVI}}$. Assim, também para Pannizza ${ }^{\mathrm{XVII}}$ Chávez foi um populista.

Sheahan ${ }^{\text {XVIII }}$ classifica a Venezuela sob Chávez como sendo populista, por ter tido ampla intervenção do Estado na economia. Javier Corrales ${ }^{\mathrm{XIX}}$ e Michael Penfold ${ }^{\mathrm{XX}}$ igualmente se enquadram no pensamento liberal crítico a Chávez. Suas inferências colocam o governo bolivariano como ditatorial e extremamente impopular. Teodoro Petkoff $^{\mathrm{XXI}}$, na mesma linha, associa o governo Chávez aos resquícios da URSS como uma esquerda autoritária, segundo ele, como Cuba. Suas críticas amparam-se na ideia, segundo a qual o presidente da República seria "personalista, com fortes traços de militarismo, messianismo, caudilhismo e autoritarismo"XXII.

Quais os equívocos das conjecturas liberais supracitadas? Pormenorizadamente, os problemas destas análises são muitos: 1) não levam em conta a história dos diversos atores sociais envolvidos no processo; 2) não concebem a diferença de interesses no seio da sociedade; 3) colocam a perspectiva do mercado como se fosse a de todos. Com efeito, elas comungam de um problema comum: são superficiais e descontextualizadas. Podemos antecipar que essas interpretações são carentes de exame mais profundo sobre a questão e que, por consequência, atendem mais a interesses políticos-ideológicos dos governantes da economia do que possuem compromissos com os fatos.

Steve Ellner ${ }^{\text {XIII }}$, por sua vez, resume o debate da primeira década dos anos 2000: alguns teóricos caracterizaram o Chavismo enquanto uma espécie de "populismo de esquerda", como Castañeda e Morales, ao passo que outros, como Marta Harnecker, entoavam o conceito de "Socialismo do século XXI". Ellner ${ }^{\text {XIV }}$ aponta que a Venezuela chavista (e demais países da onda "bolivariana") não se aproxima de nenhum caso real de esquerda historicamente observados: o Chavismo não encontra total semelhança nem com os regimes políticos aceitos e entendidos como parte do "socialismo real" (China, URSS, Cuba, por ex.), nem com outras escolas de esquerda clássica, como a linha social-democrata, que governou brevemente, ainda que exercendo considerável influência na social-democracia europeia durante o século XX. Tampouco o Chavismo se entende tendo em vista o populismo clássico. Em suma, para este autor "O modelo híbrido emergente, combinando as dimensões da democracia radical e a democracia representativa herdada do passado, também é, em muitos aspectos, sui generis" ${ }^{\mathrm{XXV}}$. Numa linha semelhante, Claudio Katz ${ }^{\mathrm{XXI}}$ entende os governos bolivarianos desta onda recente como nacionalistas radicais.

Demais acadêmicos também buscaram descrever e conceituar o Chavismo em outras bases analíticas. Raphael Seabra ${ }^{\text {XVII }}$, ao perguntar no título de seu trabalho se estaríamos testemunhando a primeira revolução do século XXI, entende que a Venezuela sob Chavismo de fato passara por uma Revolução Bolivariana, constituída por, ao menos, três etapas: a "etapa Constituinte da Revolução" (1990-2001); a "etapa Nacional-Soberana da revolução" (2001-2005); e, por fim, a "etapa de construção da via venezuelana ao socialismo" (20062012). Contudo, escrevendo o autor em 2012, ainda estaríamos presenciando uma construção, e não uma etapa de Socialismo pleno em território venezuelano. Em uma linha similar, Fermin e Soteldo XXVIII apontam que o "modelo societal capitalista, configurado en la formación histórica de Venezuela desde la época de la colonia, que en nuestro días se resiste a 


\section{O CHAVISMO IMPLANTOU O SOCIALISMO NA VENEZUELA? UM ESTUDO DE CASO SOBRE COMO CONCEITUAR ECONOMIAS CONTEMPORÂNEAS}

\section{LUCAS LEMOS WALMRATH \\ WALLACE DE MORAES}

ser desmontado y sustituido por el llamado socialismo bolivariano, como se bautiza al llamado nuevo socialismo del siglo XXI".

Também não considera a Venezuela um país propriamente socialista Raúl Zelik ${ }^{\mathrm{XXIX}}$, ao apontar que o país ainda avançava para superar o modelo rentista do petróleo, não sendo claras as metas e objetivos para transformação proposta pelo Socialismo do Século XXI. Ao comparar as transformações sociais conduzidas pelo Chavismo com a Revolução cubana, Eliane Soares ${ }^{\mathrm{XX}}$ destaca que, "no caso cubano, a revolução socialista foi simultânea à revolução nacional-democrática e, no caso venezuelano, está se buscando avançar por vias graduais da revolução nacional-democrática ao socialismo.", descartando a leitura de que o país já tenha alcançado sua fase socialista.

Conclui-se desta breve pesquisa à literatura que, ao menos, o Chavismo se encontra no campo à esquerda dos movimentos e práticas políticas, herdando conceitos e inspiração no Socialismo, mas sendo um fenômeno muito característico, a sua própria maneira. É preciso dizer que a literatura especializada não nos ajudou muito com o propósito deste trabalho: apesar de também problemática e insuficiente, a nosso ver, para conceituar o Chavismo, a academia se preocupa demasiadamente em conceituar a forma do governo Chavista e seus traços principais, e não a economia venezuelana em suas transformações sob o período chavista. Além disto, muitas das vezes, os acadêmicos consultados parecem simplesmente assumir o conceito de Socialismo do Século XXI como sinônimo do período atual do Chavismo, sem precisar ou especificar o uso do conceito.

A seguir, contrastamos o debate acadêmico com os entendimentos conceituais providenciados por críticos do Chavismo: é nestas críticas onde residem as alegações de um suposto Socialismo Chavista na Venezuela, especialmente as advindas dos oligopólios de comunicação de massa, governantes socioculturais da grande mídia ${ }^{\mathrm{XXI}}$ críticos do governo Chavista. Por outro lado, os próprios Chavistas, incluindo o próprio Chávez, muitas das vezes incorporaram o conceito de Socialismo do século XXI ${ }^{\mathrm{XXXI}}$, fato este que pode ter colaborado para a presente confusão conceitual. Por exemplo, Seabra aponta ${ }^{\text {XXIII }}$ que há no país certa "convicção oficial de que o socialismo já é parte da realidade cotidiana da Venezuela, sendo assim, do ponto de vista do próprio governo bolivariano as discussões sobre o que seria $o$ socialismo do século XXI é uma questão superada".

Por sua vez, o renomado jornal econômico The Economist ${ }^{\mathrm{XXXIV}}$, em um recente artigo avaliando como Chávez e Maduro haviam empobrecido a Venezuela em seus governos, mencionava a política econômica chavista como imprudente no que diz respeito a relação com o petróleo como sendo responsável pela crise econômica do "Venezuelan socialism". Em um artigo de opinião no New York Post, Rich Lowry ${ }^{\mathrm{XXV}}$ afirmava com todas as letras que a Venezuela era um país devorado pelo socialismo. Jason Mitchell ${ }^{\mathrm{XXXI}}$, escrevendo em sua coluna como correspondente na Venezuela para o The Telegraph, criticava o recente caos social venezuelano como induzido pelo socialismo, aproveitando ainda para atacar Jeremy Corbyn, representante da esquerda partidária mais aguerrida da Inglaterra.

No entanto, mesmo na grande mídia comercial havia espaço para discordância, ainda que estas fossem exceções. Em um artigo peculiar, a notoriamente conservadora FOX News XXXVII estadunidense apontava que a Venezuela não era um país socialista, mesmo com todos os esforços de Chávez. O tira-teima era simples: a maior parte da economia venezuelana ainda estava em mãos privadas, e não estatais. $\mathrm{O}$ artigo também notava como as estatizações eram mal apreciadas em geral, discutindo também como o capitalismo ia de vento em popa nas ilhas de riqueza e consumismo da elite venezuelana.

Em suma, contrariamente ao aparente consenso cunhado pelos oligopólios de comunicação de massa acerca da Venezuela, a literatura, especialmente a advinda da Ciência 


\section{O CHAVISMO IMPLANTOU O SOCIALISMO NA VENEZUELA? UM ESTUDO DE CASO SOBRE COMO CONCEITUAR ECONOMIAS CONTEMPORÂNEAS}

\section{LUCAS LEMOS WALMRATH \\ WALLACE DE MORAES}

Política, não produziu um conceito consensual acerca do fenômeno do Chavismo. Nem mesmo categoriza a Venezuela chavista como socialista plenamente, especialmente em seu sentido econômico, alegação midiática frequente, tendo em vista as medidas estatistas de Chávez e Maduro. Exposta esta breve discussão bibliográfica e midiática acerca do tema, na próxima seção discutiremos a abordagem escolhida no intento de avaliar, política e economicamente, a Venezuela durante o Chavismo.

\section{METODOLOGIA}

Nossos procedimentos metodológicos são os seguintes: 1) faremos um estudo do caso venezuelano sob a governança política de Chávez, em que pese uma breve comparação da Venezuela com demais países em alguns indicadores; 2) Conduzimos uma pesquisa bibliográfica em dicionários especializados, com foco nas disciplinas de Economia e Ciência Política, além de uma pesquisa documental em fontes secundárias, abarcando mídia eletrônica, documentos institucionais e oficiais; 3) realizaremos ainda uma breve análise de dados qualitativos e quantitativos.

Para verificar e, posteriormente, classificar a Venezuela sob o Chavismo, optamos por uma análise não só da forma de governo em seus traços gerais, mas em seus componentes institucionais, em termos dos aparelhos do Estado/governo e, principalmente, da configuração dominante da economia neste período.

Estudamos e sintetizamos os conceitos de Capitalismo e Socialismo nos seguintes dicionários: The MIT Dictionary of Modern Economics (1992); Novíssimo Dicionário de Economia (1999); Routledge Dictionary of Economics (2002); A Dictionary of Economics (2003); Dicionário de Política, de Norberto Bobbio, Nicola Matteucci e Gianfranco Pasquino (1998); The Routledge Dictionary of Politics (2004); Oxford Concise Dictionary of Politics (2009) e, por fim, o Dicionário do pensamento marxista (1988).

\section{RESULTADOS}

Para se analisar a validade conceitual da Venezuela enquanto um país socialista, é necessário antes resgatar as principais definições conceituais de Socialismo. Sabemos que, desde tempos imemoriais, diversas concepções de socialismo foram criadas e elas tratam de temas centrais da economia política de maneira bem dessemelhante. Portanto, não podemos descuidar da história do conceito, tampouco que ele comporta alguns aspectos centrais que não podem ser deixados de lado. Em resumo, toda categoria, embora possa mudar ao longo do tempo, é composta por um mínimo comum que a singulariza e, principalmente, a diferencia de outras.

De acordo com Bottomore ${ }^{\mathrm{XXVIII}}$, as raízes históricas do socialismo remontam ao movimento radical dos Diggers, na Inglaterra, no período da Guerra Civil inglesa, no século XVII. Babeuf, durante a Revolução Francesa, e os chamados, por Marx e Engels, de utópicos (Owen, Fourier e Saint Simon) também defenderam o conceito nos séculos XVIII e XIX. Cesare Pianciola ${ }^{\text {XXIX }}$ asseverou que o sentido moderno de socialismo foi adquirido nos programas de cooperação entre os operários de gestão comum dos meios de produção, propugnados pelos owenianos nos finais dos anos de 1820 . Woodcock ${ }^{\mathrm{XL}}$ defendeu que as ideias do anarquismo, uma das possibilidades de socialismo, tiveram suas origens na crítica social dos líderes camponeses da Inglaterra e da Alemanha, durante os séculos XIV e XVI, respectivamente, baseado no ataque simultâneo à propriedade e à autoridade. Max Nettlau ${ }^{\mathrm{XLI}}$ foi mais longe, encontrando no pensamento 


\section{O CHAVISMO IMPLANTOU O SOCIALISMO NA VENEZUELA? UM ESTUDO DE CASO SOBRE COMO CONCEITUAR ECONOMIAS CONTEMPORÂNEAS}

\section{LUCAS LEMOS WALMRATH \\ WALLACE DE MORAES}

de Carpócrates, da escola gnóstica, no século II, no Egito, indícios claros da defesa de um tipo de socialismo. Sam Mbah e Igariwey ${ }^{\text {XLII }}$ mostraram a existência de uma espécie de comunismo primitivo em África. Pierre Clastres ${ }^{\text {XLIII }}$ expôs como as sociedades indígenas na América lutaram contra a existência de Estado e da propriedade privada.

Certo é que o referido conceito teve múltiplos significados ao longo da história. Em comum, se apresentam em contraposição ao escravismo, ao feudalismo e ao capitalismo. No entanto, um bom conceito não pode se fazer a partir de suas negações. É preciso entender o que propõe os socialistas. Podemos dizer que buscavam, de alguma forma, justiça social e igual distribuição daquilo que era gerado pela comunidade, sempre postulando, se não a igualdade total, pelo menos, a diminuição drástica das desigualdades produzidas por outros sistemas.

Dessas propostas de socialismo, duas ainda permanecem com força e é com elas que debateremos: o socialismo anarquista e o socialismo marxista. A discussão a partir do conceito de socialismo libertário dos anarquistas ${ }^{\text {XIV }}$ pressupõe o autogoverno, sem a dicotomia entre governantes e governados, sem Estado, estando os trabalhadores organizados de modo a gerir o produto de seu trabalho autonomamente, sem a intervenção de qualquer patrão ou autoridade, que nesse modelo não podem existir. Ajuda mútua, coletivismo, autogestão e comunismo anarquista são conceitos caros dessa corrente.

A partir de um outro veio analítico, e muito mais difundido, temos as concepções de Karl Marx e Friedrich Engels. Esses autores são expoentes de uma das interpretações mais clássicas acerca do socialismo. O Manifesto Comunista ${ }^{X L V}$, reverenciado em todo o mundo pelos seus seguidores, é a publicação mais importante sobre o assunto desta corrente. Chamamos a atenção para o papel do Estado na sociedade comunista futura ideal, de Marx e Engels, caracterizado por controlar praticamente todos os meandros da vida social. A propriedade privada revela-se como capital objeto de ataque, apontada por eles como principal expressão do modo de produção capitalista. Em resumo, no projeto socialista dos autores, o Estado controlaria toda a economia, fenecendo a propriedade privada, com a finalidade de garantir a igualdade social.

Resgatadas as principais marcas dos socialismos marxista e libertário, podemos agora apresentar o contraste das interpretações conceituais acerca de socialismo com o seu oposto, o capitalismo, a partir de uma síntese elaborada por oito dicionários especializados. Vejamos:

Quadro 1 - Síntese das principais características dos conceitos de Socialismo e Capitalismo segundo dicionários especializados consultados:

\section{Capitalismo}

Socialismo

Propriedade privada dos meios de produção, Propriedade comum/estatal dos meios de troca e distribuição: controle e decisões produção, troca e distribuição: controle e econômicas concentrados nos decisões econômicas concentrados nos $\operatorname{proprietários~}^{\mathrm{XLVI}}$ trabalhadores e/ou no Estado ${ }^{X L V I I}$

Produção motivada pelo lucro ${ }^{\text {XLVIII }}$ Produção motivada pela distribuição da riqueza social $^{\mathrm{XLIX}}$

Economia de mercado não (inteiramente) Economia planificada pelo Estado; economia planificada pelo Estado ${ }^{\mathrm{L}} \quad$ mista de mercado e Estado; economias de 


\title{
O CHAVISMO IMPLANTOU O SOCIALISMO NA VENEZUELA? UM ESTUDO DE CASO SOBRE COMO CONCEITUAR ECONOMIAS CONTEMPORÂNEAS
}

\section{LUCAS LEMOS WALMRATH \\ WALLACE DE MORAES}

\author{
mercado $^{\mathrm{LI}}$
}

Diferentes níveis de intervenção e regulação Diferentes níveis de intervenção e regulação estatal na economia ${ }^{\text {LII }}$

estatal na economia ${ }^{\text {LIII }}$

Mercado de trabalho assalariado ${ }^{\text {LIV }}$ Mercado de trabalho assalariado no Socialismo-estatal

Maioria dos empregadores e empregados no Trabalhadores empregados em empresas setor privado $^{\mathrm{LV}} \quad$ estatais ou cooperativas autogestionadas

Fonte: Elaboração própria com base nos dicionários descritos na seção de Metodologia

Após esclarecer os constituintes mínimos requeridos para se enquadrar uma economia em um dos sistemas acima, apresentaremos dados para testar a hipótese de que a Venezuela seria um exemplo de economia socialista.

O cerne da definição Socialista reside, conforme demonstrado na síntese conceitual, numa economia baseada na propriedade comum dos meios de produção, troca e distribuição, coletiva, (socialismo libertário) ou estatal (socialismo marxista); nesta, o controle e as decisões econômicas seriam concentrados no Estado e naquela nos próprios trabalhadores por meio da autogestão.

O quanto a estrutura da economia venezuelana durante o chavismo se alterou em prol de uma maior participação do Estado? Uma pista reside numa análise da participação do PIB quando separado nos dois principais setores: público e privado. Se o chavismo de fato implementou um programa socialista estatal, deveríamos esperar um crescente percentual do setor público, tanto por sua expansão em gastos em programas sociais mas, principalmente, pela estatização progressiva das empresas de todos os setores. No entanto, não é isto que verificamos: ao analisar o percentual relativo a cada ano percebemos que a participação do Estado no PIB nacional não aumentou dramaticamente. Mais que isso, durante o chavismo o percentual da participação estatal sequer aumentou em relação aos dois anos pré-chavismo, 1997 e 1998.

Figura 1 - Participação (em \%) dos setores público e privado no PIB venezuelano, 19972013 


\section{O CHAVISMO IMPLANTOU O SOCIALISMO NA VENEZUELA? UM ESTUDO DE CASO SOBRE COMO CONCEITUAR ECONOMIAS CONTEMPORÂNEAS}

\section{LUCAS LEMOS WALMRATH \\ WALLACE DE MORAES}

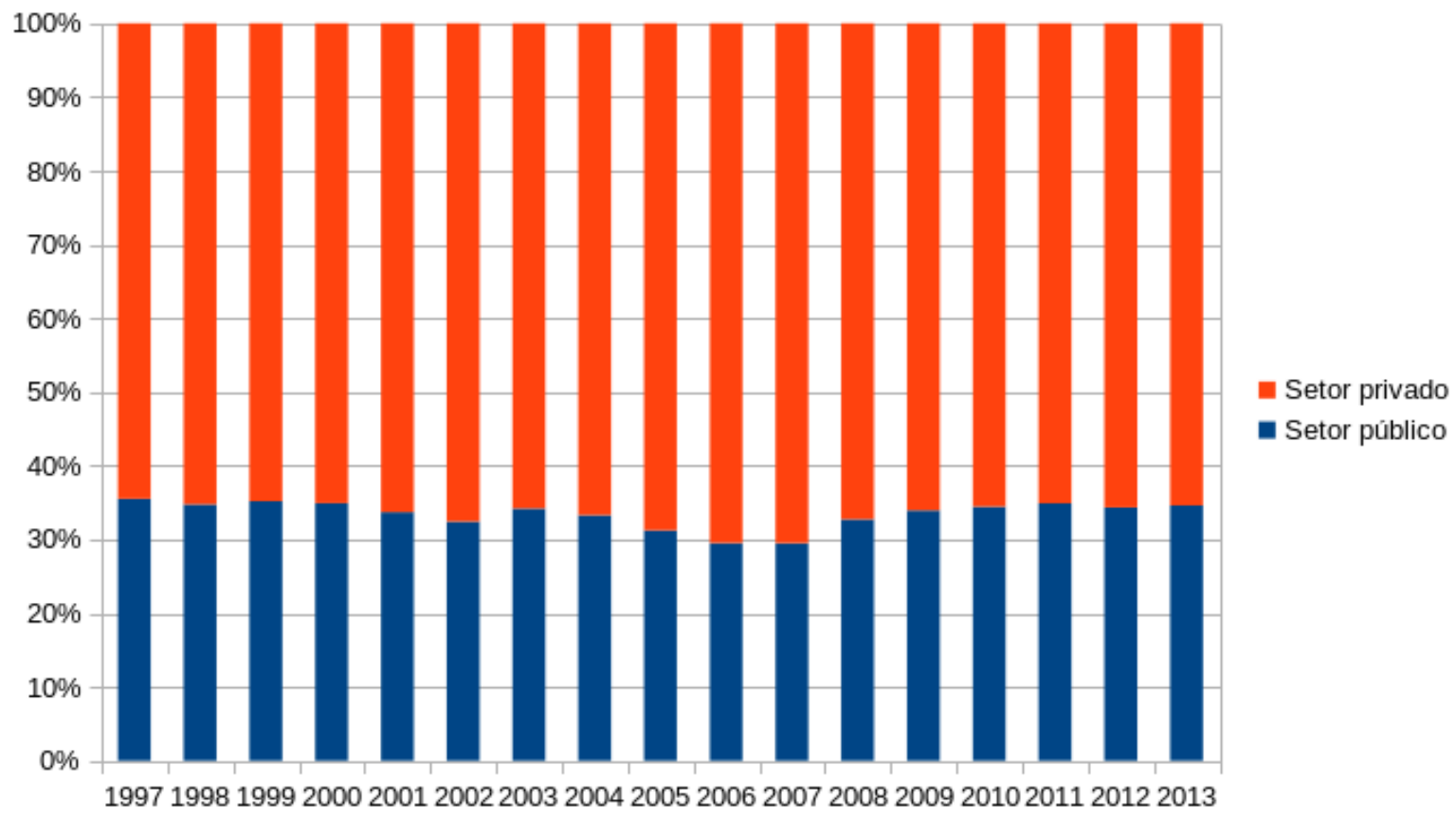

Fonte: Elaboração própria a partir dos dados do Banco Central de Venezuela, 2019a

Alguém poderia argumentar que empresas estatais representam um percentual menor, mas muito relevante nas economias; e, dado intervencionismo de inspiração socialista do Chavismo, o controle das empresas estatais e de seus empregos seriam uma evidência suficiente para justificar o socialismo venezuelano. De fato, o controle sobre a PDVSA, empresa estatal produtora de petróleo na Venezuela, confere grande agência ao governo chavista, tendo em conta como o petróleo segue sendo o produto chave da economia deste país. No entanto, um resultado muito parecido é obtido quando se analisa o PIB venezuelano por classes econômicas ${ }^{\mathrm{LVI}}$. Novamente, é possível ver que os setores privados, não petrolíferos, continuam a produzir a maior parte do PIB venezuelano: os governos chavistas não conseguiram alterar dramaticamente os percentuais em relação ao período antecessor, como visto nos dados para 1997 e 1998.

Figura 2 - Participação (em \%) por classe de atividade econômica no PIB venezuelano, $1997-2013$ 
LUCAS LEMOS WALMRATH

WALLACE DE MORAES

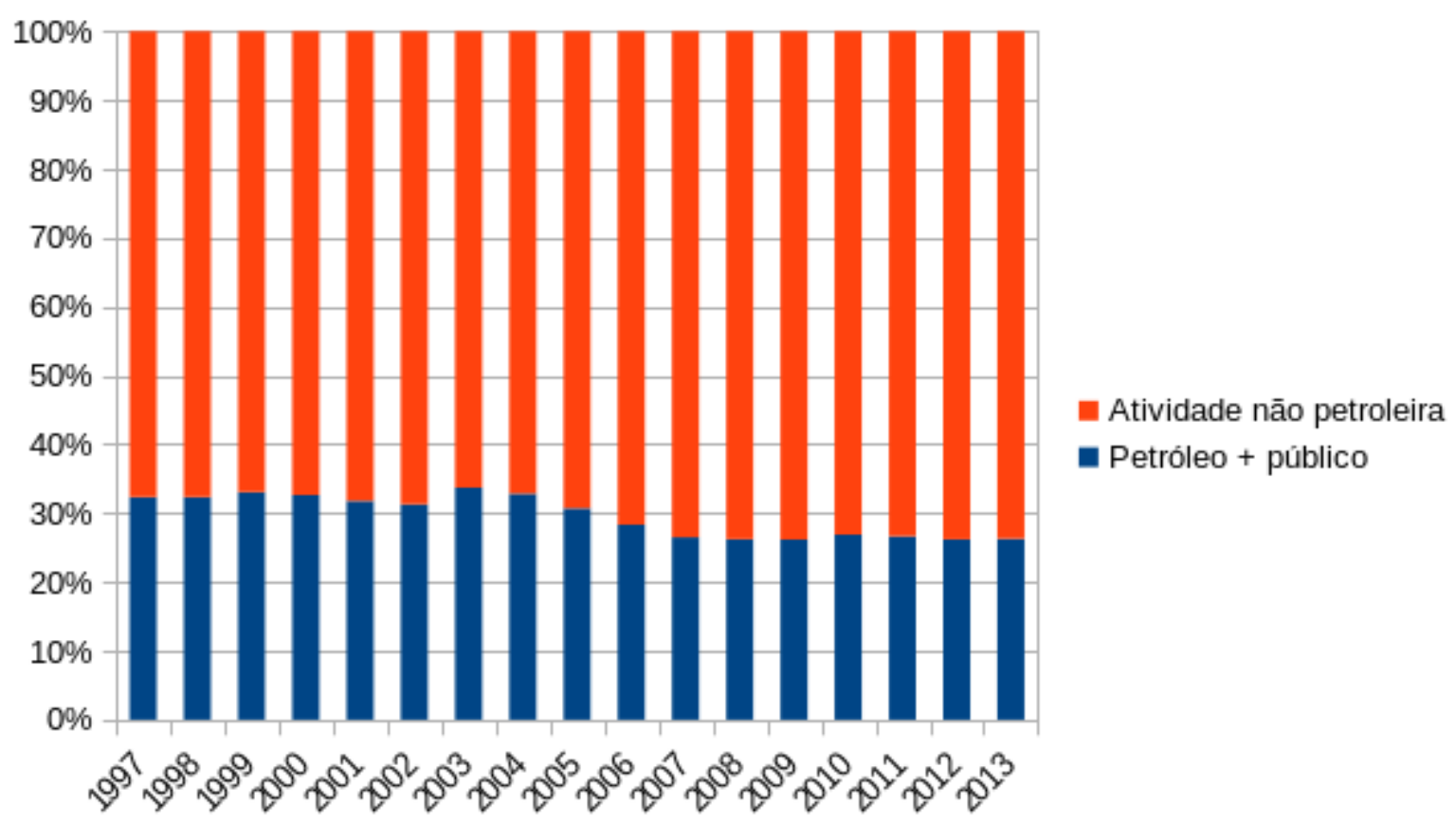

Fonte: Elaboração própria a partir dos dados do Banco Central de Venezuela, 2019b

Em consonância com esta argumentação, ainda levando em consideração a hipótese estatal e as definições conceituais apresentadas, levantamentos realizados na primeira década da Era Chávez apontavam que os servidores públicos na Venezuela respondiam por $18,4 \%$ da força de trabalho nacional. Em comparação, servidores públicos no EUA, exemplo liberal de Estado mínimo, contavam 14,2\% da força de trabalho nacional, ao passo que, na Europa, em muitos países a mesma cifra respondia por mais de $20 \%$ da força de trabalho empregada pelo Estado $^{\text {LVII }}$.

Figura 3 - Percentual de empregados no setor público e privado venezuelano, referência para o mês de dezembro 


\section{O CHAVISMO IMPLANTOU O SOCIALISMO NA VENEZUELA? UM ESTUDO DE CASO SOBRE COMO CONCEITUAR ECONOMIAS CONTEMPORÂNEAS}

\section{LUCAS LEMOS WALMRATH \\ WALLACE DE MORAES}

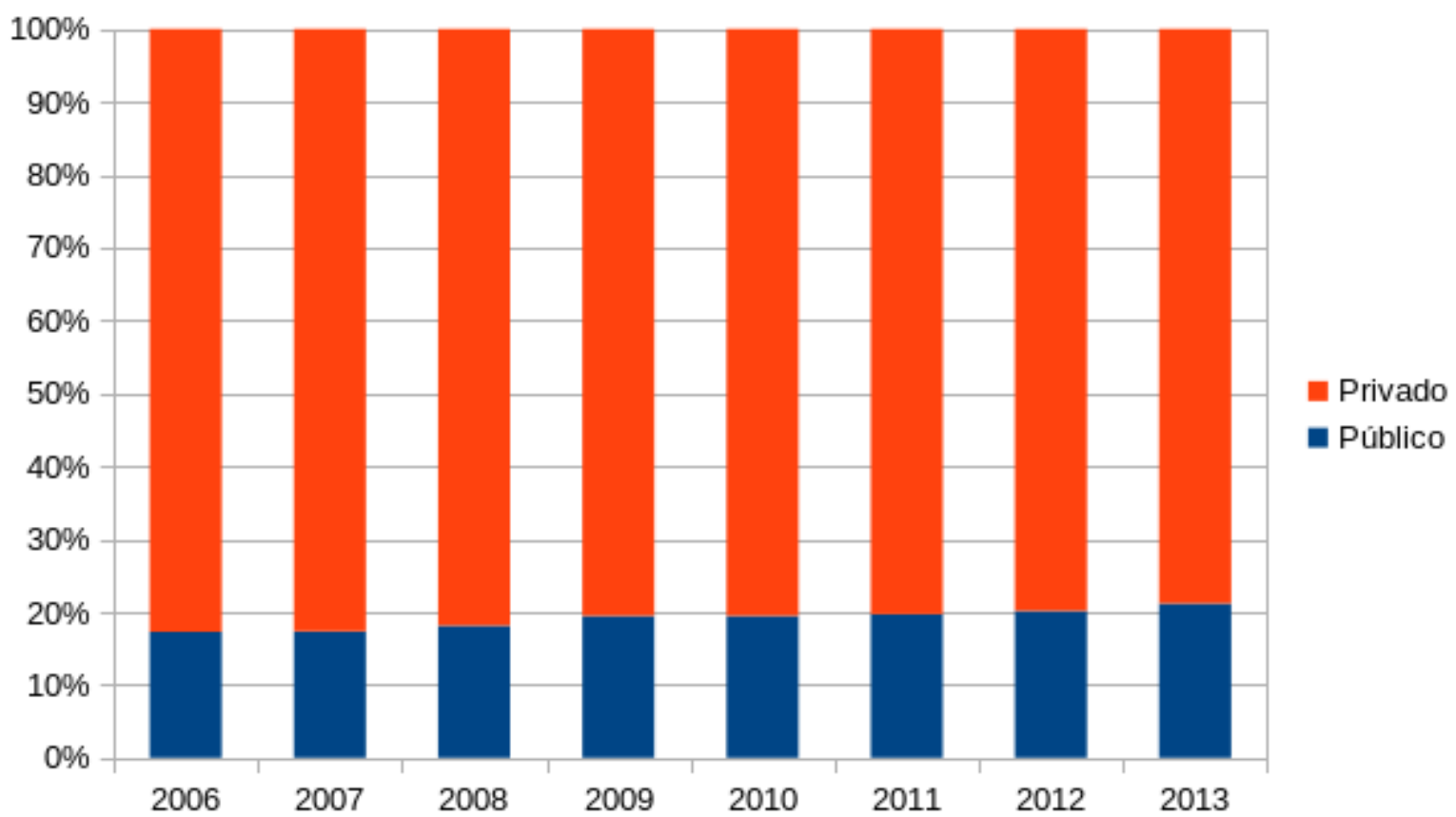

Fonte: Encuesta de Hogares por Muestreo - Instituto Nacional de Estadística, INE. Disponível em http://www.ine.gov.ve/index.php?option=com content\&view=category\&id=103\&Itemid=40\#. Acesso em $03 \mathrm{de}$ fevereiro de 2020 .

Além disto, outros indicadores parecem ir contra a hipótese: ao menos na primeira década de governo Chávez, o setor privado, que deveria diminuir consideravelmente (ou mesmo ser extinto) em um país socialista de facto, cresceu mais rápido que o setor público-estatal nos primeiros 8 anos de Chavismo ${ }^{\text {LVIII }}$. Mais que isso, o setor privado respondia por uma fatia maior da economia venezuelana em 2007 do que antes do início do Chavismo, isto considerando 8 anos de governo já decorridos ${ }^{\text {LIX }}$, fato também observado neste trabalho.

Instituições especializadas, que não midiáticas, também produziram pareceres relevantes sobre a Venezuela. Nenhum dos documentos consultados, contudo, menciona o suposto socialismo de Chávez, em que pese as críticas ao governo: nem mesmo em pareceres especializados em Economia, tais como o apresentado pelo Banco Mundial ${ }^{\mathrm{LX}}$. O World Factbook $^{\mathrm{LX}}$, desenvolvido pela agência de inteligência estadunidense, aponta para as críticas comumente feitas ao Chavismo: autoritarismo na esfera política e civil somado a um maior controle da economia. Contudo, não consta o uso do conceito de Socialismo para descrever a economia e a política venezuelana.

Em uma análise das instituições que guiam o entendimento e as operações de propriedade no país, podemos ver como a Constituição bolivariana garante, formalmente, propriedades privadas, estatais e sociais e mistas ${ }^{\mathrm{LXII}}$. De fato, o Chavismo galgou em medidas associadas a programas socialistas $^{\text {LXIII }}$, tais como expropriações e reestatizações de setores industriais estratégicos; reforma agrária; controle de preços; promoção de cooperativas sociais; e, por fim, políticas de redistribuição, chamadas de misiones sociales ${ }^{\text {LXIV }}$.

Dando continuidade a análise dos componentes estatais que nos ajudam a decifrar a questão posta, a República Bolivariana da Venezuela se afirmava ${ }^{\mathrm{LXV}}$ um Estado Social e Democrático de Direito e de Justiça. Como forma de governo, em termos formais o país era regido como uma República federal presidencialista. A divisão do Poder Público Nacional se fazia por meio dos poderes Legislativo, Executivo, Judicial, Cidadão e Eleitoral. Vigorava no país, como órgão legislativo nacional, a Asamblea Nacional de Venezuela, sendo um regime 


\section{O CHAVISMO IMPLANTOU O SOCIALISMO NA VENEZUELA? UM ESTUDO DE CASO SOBRE COMO CONCEITUAR ECONOMIAS CONTEMPORÂNEAS}

\section{LUCAS LEMOS WALMRATH \\ WALLACE DE MORAES}

unicameral. Politicamente, a Venezuela era configurada como uma democracia representativa, com frequente uso de plebiscitos e referendos, havendo competição pluripartidária. Não julgamos aqui o mérito e a veracidade de tais configurações: nos interessa apenas descrever como o Estado venezuelano se afirmava em termos formais.

Desta breve descrição, ainda que o cerne do debate resida na estrutura econômica, podemos ver, como já ressaltado anteriormente por Ellner, que a estrutura política venezuelana seguia o modelo dominante na contemporaneidade ocidental, muito mais assemelhado com os países liberais capitalistas do que com as antigas experiências socialistas estatais do leste europeu, por exemplo. Em que pese, o chavismo afirmar que implementara o socialismo do século XXI e os seus opositores afirmarem se tratar de regime populista ditatorial.

\section{Breve análise das políticas públicas adotadas pelo chavismo: uma Plutocracia Social- Democrata de las calles}

Existem diversas maneiras possíveis de se conceituar economias contemporâneas: muitas já foram propostas, e os debates não cessam por serem tanto normativos quanto científicos. Contudo, não podemos desprezar condições necessárias, suficientes e mínimas para se aventar uma conceituação no lugar de outra. Neste artigo, propusemos avaliar as políticas públicas postas em prática pelo Chavismo (1999-2013) e o tipo majoritário de propriedade dos meios de produção garantidos pela lei no país. Para isto, é fundamental atentar para os eixos econômico e político: para os constituintes essenciais da economia e do Estado que se busca analisar. Como visto, ao adentrarmos a discussão econômica, é de extrema relevância estar seguro acerca da estrutura econômica geral disposta. Paralelamente, quanto ao Estado, devese atentar, no mínimo, à Constituição e ao modelo político predominante no país. Ademais, é preciso desenhar uma linha precisa nos estudos comparativos, buscando similaridades e particularidades em cada caso analisado.

Para demonstrar como o problema colocado neste artigo pode ser enfrentado e lido de diversas maneiras, finalizamos com uma leitura socialista libertária da questão. Apesar dos grandes avanços sociais empreendidos pelo movimento bolivariano-chavista, com grande mérito para a mobilização e organização popular do mesmo, as transformações que há pouco tempo completaram 20 anos não deram conta de conduzir uma cisão completa com o sistema capitalista. Especialmente após a morte de Chávez, ficou nítido para populares e críticos como o movimento se apoiava em sua figura, excessivamente carismática, para o bem e para o mal.

Objetivamos aqui perceber se as principais políticas públicas adotadas durante a governança política chavista podem ser enquadradas como socialistas (libertárias ou marxistas) ou capitalistas (liberais ou social-democratas). Antes de respondermos a essas questões, é mister estabelecermos algumas advertências, posto que é premente definir qual foco de análise teórica utilizaremos: a) do capitalismo de Estado; b) do socialismo marxista; c) do socialismo libertário. Feitas as necessárias ressalvas, podemos olhar a Era Chávez por diferentes ângulos. Vamos ao primeiro passo.

Chávez assumiu o governo em 1999, auge do neoliberalismo. Naquele momento, as chamadas liberalizações estavam sendo implementadas em todo o mundo. Sua governança foi a primeira a romper com o Consenso de Washington em toda a América Latina, quando outros afirmavam que era impossível lutar contra as forças do mercado.

Do ponto de vista do capitalismo de Estado, baseado em uma interpretação tipicamente social-democrata, a governança política de Chávez foi exemplar. Garantiu uma forte intervenção estatal na economia. Reestatizou várias empresas. Construiu novas 


\section{O CHAVISMO IMPLANTOU O SOCIALISMO NA VENEZUELA? UM ESTUDO DE CASO SOBRE COMO CONCEITUAR ECONOMIAS CONTEMPORÂNEAS}

\section{LUCAS LEMOS WALMRATH \\ WALLACE DE MORAES}

estatais. Ampliou direitos sociais. Incrementou significativamente os direitos trabalhistas. Forneceu créditos para os micro e pequenos empresários. Democratizou decisões políticas por meio de referendos e plebiscitos. Criou diversas missões sociais para erradicar o analfabetismo, distribuir alimentos e ampliar atendimentos de saúde por meio de proliferação de postos médicos; dentre elas estão: "Misión Barrio Adentro", que levou atendimento de saúde gratuito para moradores carentes; "Misión Ribas", que acabou com o analfabetismo; "Misión Habitat" e "Misión Vivienda", que criaram casas populares e programa habitacional. Afora as missões, o governo implantou o Mercado Popular (MERCAL), que vendia comida subsidiada. Foram criados seis mil restaurantes comunais, com a comida sendo preparada na própria casa das pessoas. Ainda foram estimulados o surgimento de cooperativas que produziam para a governança política. Devemos contar, também, a criação de universidades e escolas públicas.

Outrossim, a perspectiva social-democrata assevera que o chavismo fez uma revolução no país, a partir dos princípios de Simón Bolívar, e implementou um modelo próprio: o "socialismo do século XXI". Este, por sua vez, advogavam seus publicistas, constituiu-se no modelo de gestão mais avançado no mundo na primeira década do novo milênio, favorecendo, exclusivamente, os trabalhadores. Podemos identificar essas interpretações nos trabalhos de Weisbrot e Sandoval ${ }^{\text {LXVI }}$, Petras ${ }^{\text {LXVII }}$ e Lander ${ }^{\text {LXVIII }}$.

A despeito das previsões dos teóricos neoliberais, as políticas social-democratas de Chávez reduziram o desemprego no país a menos da metade e fizeram com que o crescimento do PIB fosse um dos mais altos do mundo, estabelecendo um crescimento considerável do IDH (Índice de Desenvolvimento Humano) ${ }^{\mathrm{LXIX}}$. É claro que o aumento do preço do petróleo ajudou e muito.

Quando focamos as políticas públicas de Chávez com o olhar do socialismo marxiano, percebemos erros e acertos. Os acertos dizem respeito às estatizações, ao crescimento do Estado, a criação de direitos para os trabalhadores. Todavia, o respeito à propriedade privada e a não estatização de todos os meios de produção constituem num grande erro para essa literatura. Além do que, nem Chávez, nem a maioria de seus ministros eram oriundos da classe operária, que teria proeminência, de acordo com o pensamento de Marx, para dirigir o processo revolucionário.

Do ponto de vista da crítica do socialismo libertário, percebemos que seu governo não tocou nas relações de produção capitalista, garantiu a propriedade privada dos meios de produção, a exploração do trabalhador pelo patrão, a divisão social e hierárquica do trabalho, enfim, instituições basilares para o pleno desenvolvimento do mercado e de sua lógica. Não houve um processo longo, contínuo e substantivo de expropriação de empresas realizada pelos governados. As poucas fábricas que passaram para a gestão dos trabalhadores logo depois foram estatizadas. Algumas tentativas de ocupação de prédios, de fábricas e de autogoverno foram plenamente rechaçadas pelo governo, em seu conjunto, e tratadas como caso de polícia. Foram criadas, aproximadamente, 140.000 cooperativas, mas que produziam para o mercado capitalista e com a mesma lógica da exploração do trabalho. Além de tudo, a governança política garantiu o Estado, fortalecendo-o. Ocorreu, também, a criminalização de dirigentes sindicais e líderes populares revolucionários ${ }^{\mathrm{LXX}}$.

A governança política de Chávez colocou na pauta do dia as bandeiras da revolução, do socialismo, junto com a crítica ao capitalismo. Isto foi uma grande vitória. Todavia, ressignificou os conceitos de socialismo e revolução, trazendo-os para o âmbito do Estado capitalista, tornando-se dependente deste, como fizeram os reformistas. O autogoverno também foi colocado na pauta, mas ficou longe de ser priorizado. 


\section{O CHAVISMO IMPLANTOU O SOCIALISMO NA VENEZUELA? UM ESTUDO DE CASO SOBRE COMO CONCEITUAR ECONOMIAS CONTEMPORÂNEAS}

\section{LUCAS LEMOS WALMRATH \\ WALLACE DE MORAES}

A Era Chávez, com base nos movimentos populares, portanto, produziu um tipo próprio de capitalismo, denominado por nós de "Plutocracia Social-Democrata de las Calles" ou "Capitalismo das Ruas", que instituiu uma "Revolução Legal”. Vejamos.

A década de 2000, na Venezuela, deve ser lida pela pressão exercida por diversos movimentos sociais. Logo após a posse de Hugo Chávez, em 1999, vários grupos sociais promoveram ocupações de prédios, terras e fábricas. Em todo o país, e desde então, as manifestações de rua se intensificaram, defendendo o rompimento com a política neoliberal e puntofijista. Ao mesmo tempo, a população pobre organizada foi trazida novamente para a participação na institucionalidade e levada, paulatinamente, a abandonar os protestos violentos contra as instituições, o capital e a ordem ${ }^{\text {LXXI }}$. A tradição inaugurada com o Caracazo criou uma "Revolução Legal", que instituiu a "Plutocracia Social-Democrata de las Calles", na Venezuela. Isto é, o capitalismo produzido foi resultado de muitas das reivindicações dos governados nas ruas, que, com absoluto respeito às leis do país, exigiram dos governantes que as mudanças fossem feitas. Com efeito, os governados foram chamados, por várias vezes, ao voto.

As mudanças estabelecidas na Plutocracia Social-Democrata de las Calles mantiveram todas as relações capitalistas de produção e reprodução do capital. O tripé sustentador do capitalismo foi mantido como a garantia da propriedade privada, da divisão social e hierárquica do trabalho e do Estado, fortalecendo-o, obstando o controle direto dos governados sobre a sua produção. Com efeito, o governo de Chávez garantiu respeito às principais instituições do regime do capital. Conquanto, embora o Estado tenha assegurado a reprodução do capitalismo, indubitavelmente, a Era Chávez diferenciou-se daquilo que fora defendido pelo pensamento liberal clássico: forte intervenção na economia, investimento no social, criação de direitos trabalhistas e regulação de preços, definitivamente, não fazem parte do rol de desejos liberais.

Durante a década de 1960, estas opções políticas eram lidas como social-democratas. Sob o governo de Chávez, podemos lê-las da mesma maneira? Pensamos que sim. Se entendemos que as políticas social-democratas na Europa foram postas em prática a partir das reivindicações do movimento operário, na Venezuela o combustível do chavismo foi o amplo movimento popular organizado. O próprio Chávez foi seu resultado, e não o contrário, como costumam defender os autoritários de plantão.

Por fim, e o mais importante, embora a maioria dos governados estivesse encampando e apoiando os conceitos de revolução e socialismo, a governança política chavista não conseguiu acabar com o capitalismo e a histórica plutocracia existente desde a chegada dos espanhóis. A exploração continuou, apesar de todo esforço discursivo e prático do presidente. As poucas cooperativas ficaram sob o jugo do mercado e não colaboram para a autogestão socialista. Os governados não conseguiram sair dessa condição. O discurso socialista e revolucionário de Chávez contrastou frontalmente com a ação da burocracia estatal e esteve muito mais para sociedade do espetáculo do que para prática real.

Concluímos que a partir de uma perspectiva social-democrata, ou de capitalismo de Estado, a Era Chávez foi um excelente exemplo. Destarte, ainda esteve muito longe para poder ser chamada de socialista; mesmo que o termo fosse ressignificado, ele não pode conter os princípios basilares do capitalismo, o regime opositor. Por tudo, entendemos que a Era Chávez pode ser mais bem caracterizada como Plutocracia Social-Democrata de las Calles.

\section{CONCLUSÃO}

O presente estudo, dadas as limitações da contribuição, da abordagem e dos dados consultados, não entende como adequada a classificação da Venezuela sob os governos de 


\section{O CHAVISMO IMPLANTOU O SOCIALISMO NA VENEZUELA? UM ESTUDO DE CASO SOBRE COMO CONCEITUAR ECONOMIAS CONTEMPORÂNEAS}

\section{LUCAS LEMOS WALMRATH \\ WALLACE DE MORAES}

Hugo Chávez como exemplo de economia socialista. Para tanto, nos amparamos na literatura especializada em conceitos políticos e econômicos. Assim, visamos contribuir para construção futura de modelos mais abrangentes, capazes de serem reproduzidos e aplicados de maneira eficaz ao se analisar e conceituar economias contemporâneas.

Com efeito, afirmamos que a Era Chávez não acabou com o capitalismo, mas, indubitavelmente, rompeu com uma de suas faces, o neoliberalismo. Ao mesmo tempo, não criou o socialismo. Todavia, implementou políticas muito fáceis de identificar, para um mínimo conhecedor da história. Trata-se de políticas social-democratas, empurradas, tal como no período do pós-guerra, por pressão dos governados. A economia venezuelana continuou capitalista, isto é, com exploração do proprietário sobre seus trabalhadores. As leis do mercado continuaram em pleno vigor. Por isso, chamaremos como um governo plutocrático, pois continuou garantindo os interesses dos donos do capital. Todavia, em que pese essa garantia, a exploração não ficou livre, mas foi amplamente regulada pelo Estado, inclusive com incremento de direitos formais para os trabalhadores ${ }^{\text {LXXVIII, }}$ por isso, não pode ser considerada como liberal, seguindo, portanto, os princípios da social-democracia. Essas políticas foram impulsionadas pelos movimentos "calleros", com os protestos de rua, assumindo papel fundamental nas escolhas de políticas públicas. Pelo exposto, denominamos a Era Chávez por Plutocracia Social-Democrata de las Calles. Embora a histórica plutocracia instalada na Venezuela há séculos fora mantida por um modo menos ultrajante para o trabalhador.

Por fim, a Era Chávez pode ser conceituada como uma "Plutocracia SocialDemocrata de las Calles". Esta produziu uma "Revolução Legal", caracterizada por atender as demandas das ruas e caminhar no sentido de desconstruir aquilo que fora imposto pela plutocracia neoliberal desavergonhada, com políticas social-democratas, gerando alto grau de instabilidade política, pois os interesses contrariados, embora de um número pequeno de eleitores, eram muito fortes política e economicamente. Nestas condições, a Venezuela passou por um momento estritamente diferente do neoliberalismo com reversão de suas políticas, mas de maneira alguma podemos chamálo de socialismo, como mostramos.

\section{NOTAS:}

${ }^{\text {I }}$ Bolsista CNPq no Mestrado em Sociologia (com ênfase em Antropologia) pelo Programa de Pós-Graduação em Sociologia e Antropologia (PPGSA) do Instituto de Filosofia e Ciências Sociais (IFCS) da UFRJ. Colaborador do Observatório do Trabalho na América Latina (OTAL) no mesmo instituto.

\footnotetext{
II Professor Associado do Departamento de Ciência Política e dos Programas de Pós-Graduação em Filosofia (PPGF) e História Comparada (PPGHC) da UFRJ. Pesquisador do Instituto Nacional de Ciência e Tecnologia (INCT/PPED). É editor da Revista Estudos libertários da UFRJ e líder do grupo de pesquisa OTAL/UFRJ. É autor de vários artigos e livros acadêmicos. Coordena a coleção "Governados por Quem? - Diferentes Plutocracias nas Américas, sendo autor de dois livros 1) História das diferentes plutocracias no Brasil e 2) A história da Venezuela que não te contaram na TV". É também autor do livro: "2013 - Revolta dos Governados ou, para quem esteve presente, Revolta do Vinagre". Desde 2018, é bolsista do Programa Jovem Cientista do Nosso Estado da FAPERJ.

III (FUKUYAMA, 2006 [1992])

IV (RODRIK, 2006)

V (CNN ESPAÑOL, 2017)

VI (DUPUIS-DÉRI, 2018)
} 


\section{LUCAS LEMOS WALMRATH \\ WALLACE DE MORAES}

VII (LÓPEZ MAYA, SMILDE, STEPHANY, 2003)

VIII (ELLNER, 2012, p. 97, tradução própria)

IX (ELLNER, 2012, p. 105, tradução própria)

$\mathrm{x}_{\text {(HAWKINS, 2003, p. 1157) }}$

${ }^{\mathrm{XI}}$ (SCHAMIS, 2006, p. 31)

XII (SCHAMIS, 2006, p. 32)

XIII (MAINWARING, 2012, p. 955)

${ }^{\mathrm{XIV}}$ (LANZARO, 2006)

Xv (PANNIZZA, 2005)

XVI (LANZARO, 2006)

XVII (PANNIZZA, 2005)

XVIII (SHEAHAN, 2002)

XIX (CORRALES, 2005; CORRALES, PENFOLD, 2007)

xx (CORRALES, PENFOLD, 2007)

XXI (PETKOFF, 2007). É importante ressaltar que Teodoro Petkoff foi ministro da economia no mandato de Carlos Andrés Pérez, caracterizado por implementar as políticas neoliberais no país que gerou o Caracazo de 1989, grande manifestação popular contra o Estado. Esse governo sofreu impeachment acusado de prática de corrupção, dentre outras denúncias.

XXII (PETKOFF, 2007)

XXIII (ELLNER, 2012, p. 98)

XXIV (ELLNER, 2012, p. 101, 111-112)

Xxv (ELLNER, 2012, p. 101, tradução própria)

${ }^{\mathrm{XXVI}}(\mathrm{KATZ}, 2007)$

XXVII (SEABRA, 2012)

XVIII (FERMIN, SOTELDO, 2014, p. 62)

XXIX (ZELIK, 2011, p. 23)

xxx (SOARES, 2010, p. 30)

XXXI (MORAES, 2019, p. 63)

XXXII (PARTIDO SOCIALISTA UNIDO DE VENEZUELA - PSUV, 2016)

XXXIII (SEABRA, 2012, p. 202) 


\section{O CHAVISMO IMPLANTOU O SOCIALISMO NA VENEZUELA? UM ESTUDO DE CASO SOBRE COMO CONCEITUAR ECONOMIAS CONTEMPORÂNEAS}

\section{LUCAS LEMOS WALMRATH \\ WALLACE DE MORAES}

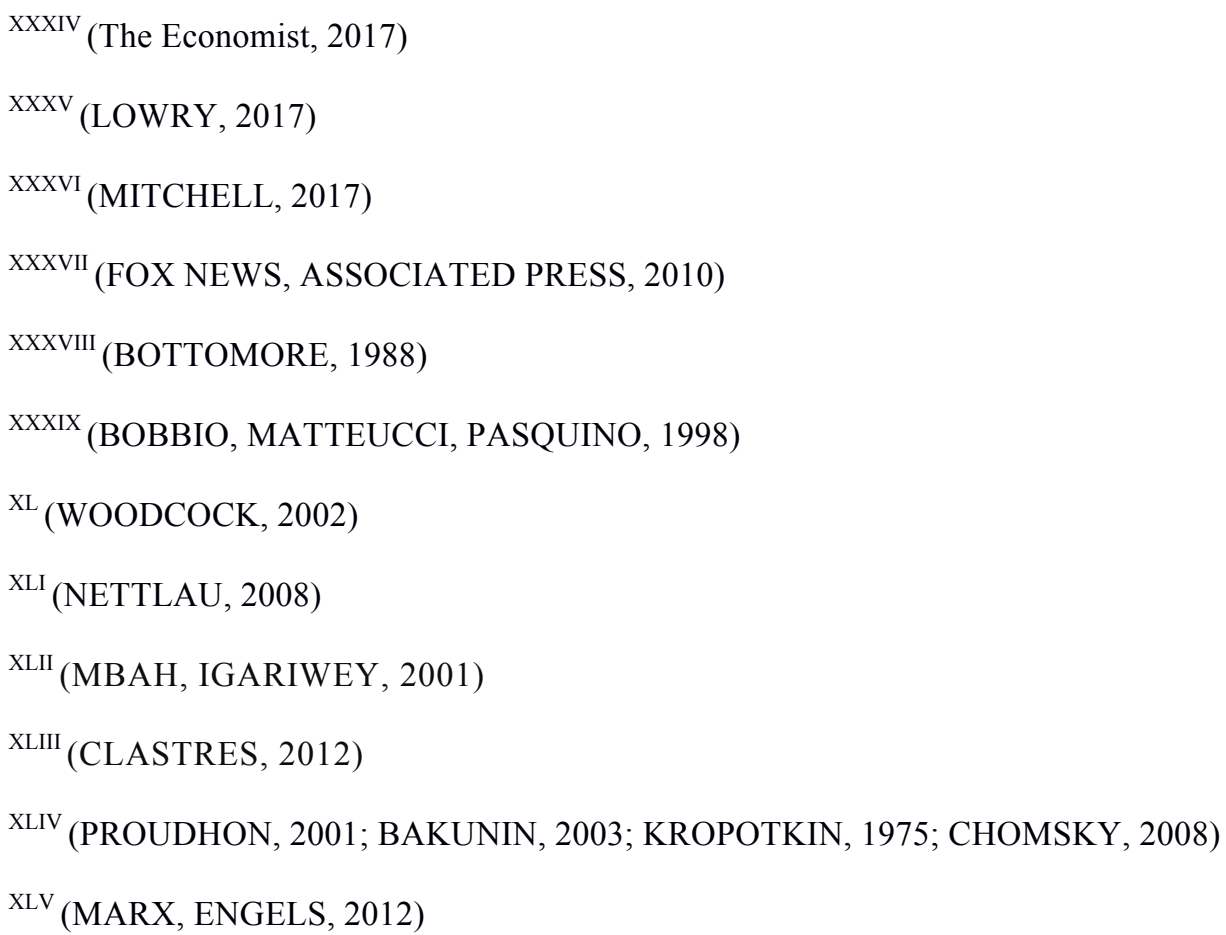
should be held by the community as a whole and administered in the interests of all" (THE MIT DICTIONARY OF MODERN ECONOMICS, 1992, p. 398)

XLVIII e.g.: "Production motivated by the profit motive" (ROUTLEDGE DICTIONARY OF ECONOMICS, 2002 , p. 91)

XLIX e.g.: "gestão tenha por objetivo promover a igualdade social (e não somente jurídica ou política), através da intervenção dos poderes públicos.” (DICIONÁRIO DE POLÍTICA, 1998, p.1197-1198)

L e.g.: "Capitalism does not imply complete laissez-faire; it is compatible with having parts of the economy in public ownership" (A DICTIONARY OF ECONOMICS, 2003); "The use of markets not planning to allocate economic resources” (ROUTLEDGE DICTIONARY OF ECONOMICS, 2002, p. 91)

LI e.g.: "Today, socialism for a whole economy is often associated with PLANNING (as in SOVIET-TYPE ECONOMIES). Some economies modified central planning by combining planning with market mechanisms, e.g. Hungary and Yugoslavia, to create MARKET SOCIALISM." (ROUTLEDGE DICTIONARY OF ECONOMICS, 2002, p. 540)

LII e.g.: "The extent to which the price mechanism is used, the degree of competitiveness in markets, and the level of government intervention distinguish the exact forms of capitalism." (THE MIT DICTIONARY OF MODERN ECONOMICS, 1992, p. 52)

LIII e.g.: "Socialists have included believers in voluntary co-operation, believers in central planning, and believers in the use of the market mechanism in running a socialist economy." (A DICTIONARY OF ECONOMICS, 2003)

LIV e.g.: "purchase of labour for money wages" (THE MIT DICTIONARY OF MODERN ECONOMICS, 1992 , p. 52) 


\section{O CHAVISMO IMPLANTOU O SOCIALISMO NA VENEZUELA? UM ESTUDO DE CASO SOBRE COMO CONCEITUAR ECONOMIAS CONTEMPORÂNEAS}

\section{LUCAS LEMOS WALMRATH \\ WALLACE DE MORAES}

${ }^{\mathrm{LV}}$ e.g: "at least a major proportion of economic activity is carried on by private profit-seeking individuals or organizations, and land and other material means of production are largely privately owned." (A DICTIONARY OF ECONOMICS, 2003)

${ }^{\text {LVI }}$ Os dados oficiais do Banco Central de Venezuela segregam a participação a classe de atividades petroleira das demais atividades econômicas. No entanto, a participação estatal existe em outras áreas. Por isso na Figura 2 somamos o percentual da classe petroleira com a do setor público, que consta em "Produc. servicios del Gobierno General".

LVII (CEPR, 2012)

LVIII (WEISBROT; SANDOVAL, 2007, p. 9)

LIX (WEISBROT; SANDOVAL, 2007, p. 9)

LX (THE WORLD BANK, 2017)

LXI (CENTRAL INTELLIGENCE AGENCY (CIA), 2018)

LXII (ÁLVAREZ, 2009)

LXIII (ELLNER, 2012). Para este autor, trata-se de uma economia mista.

LXIV (MORAES, 2019)

${ }^{\mathrm{LXV}}$ Até a escrita deste artigo, que se refere em especial a Venezuela durante os governos Chavistas.

${ }^{\text {LXVI }}$ (WEISBROT; SANDOVAL, 2007)

LXVII (PETRAS, 2007)

LXVIII (LANDER, 2005)

LXIX (WEISBROT; SANDOVAL, 2007)

${ }^{\text {LXX }}$ Ver Uzcátegui (2010).

LXXI Durante a governança política de Chávez, os protestos de rua tenderam a declinar. Ver López Maya, (2003, 164).

LXXII (DEBORD, 1997)

LXXIII (MORAES, 2019)

\section{BIBLIOGRAFIA}

ÁLVAREZ, Victor. Venezuela: ¿Hacia dónde va el modelo productivo? 1a ed. Caracas: Centro Internacional Miranda (CIM), 2009. Disponível em: $<$ http://209.177.156.169/libreria_cm/archivos/pdf_199.pdf >. Acesso em: 3 out. 2018.

A Dictionary of Economics. 2a ed. [S.1.]: Oxford University Press, 2003.

BAKUNIN, Mikhail. (2003) Estatismo e anarquia. São Paulo: Imaginário. 


\section{O CHAVISMO IMPLANTOU O SOCIALISMO NA VENEZUELA? UM ESTUDO DE CASO SOBRE COMO CONCEITUAR ECONOMIAS CONTEMPORÂNEAS}

\section{LUCAS LEMOS WALMRATH \\ WALLACE DE MORAES}

BANCO CENTRAL DE VENEZUELA (2019a). Producto Interno Bruto por Sectores Institucionales, a Precios Constamtes, $1997-2013$. Disponível em: http://www.ine.gov.ve/index.php?option=com_content\&view=category\&id=100\&Itemid=59. Acesso em: 8 set 2019

(2019b). Producto Interno Bruto por Sectores Institucionales, a Precios Constamtes, $1997 \quad-\quad 2013.2$ Disponível em: http://www.ine.gov.ve/index.php?option=com_content\&view=category\&id=100\&Itemid=59. Acesso em: 8 set 2019

BOTTOMORE, Tom. Dicionário do pensamento marxista. [S.1.]: Zahar, 1988.

BOBBIO, Norberto; MATTEUCCI, Nicola; PASQUINO, Gianfranco (Orgs). Dicionário de Política. $11^{\mathrm{a}}$ ed. Brasília: Editora UNB, 1998.

CENTRAL INTELLIGENCE AGENCY (CIA). The World Factbook - Venezuela. Governamental. Disponível em: $<$ https://www.cia.gov/library/publications/the-worldfactbook/geos/ve.html>. Acesso em: 22 abr. 2018.

CEPR. Public Sector Employment in Venezuela Is Not So Large as the Associated Press Suggests. 2012. Disponível em: <http://cepr.net/blogs/the-americas-blog/public-sectoremployment-in-venezuela-is-not-so-large-as-the-associated-press-suggests $>$. Acesso em: 18 abr. 2018.

CHOMSKY, NOAM. (2008) Razões de Estado. Rio de Janeiro: Record.

CLASTRES, Pierre. (2012). A sociedade contra o Estado - pesquisa de antropologia política. São Paulo: Cosac Naify.

CNN ESPAÑOL. Trump: "La dictadura socialista de Maduro ha causado dolor en el pueblo". CNN Español, 19 set. 2017. Disponível em: <https://cnnespanol.cnn.com/2017/09/19/trumpla-dictadura-socialista-de-maduro-ha-causado-dolor-en-el-pueblo/> . Acesso em: 21 abr. 2018.

CORRALES, Javier. (2005), "In Search of a Theory of Polarization: Lessons from Venezuela, 1999/2005”. Revista Europea de Estudios Latinoamericanos y del Caribe, n. 79.

; PENFOLD, Michael. (2007) "Venezuela: Crowding Out the Opposition". Journal of Democracy, v. 18, n. 2.

DEBORD, Guy. (1997) A sociedade do espetáculo. São Paulo: contraponto.

DUPUIS-DÉRI, Francis. (2018) “'Who's afraid of the people? The debate between political agoraphobia and political agoraphilia"”. Global Discourse, 8(2), 238-256, https://doi.org/10.1080/23269995.2018.1468607

ELLNER, Steve. The Distinguishing Features of Latin America's New Left in Power: The Chávez, Morales, and Correa Governments. Latin American Perspectives, v. 39, n. 1, p. 96114, jan. 2012. 


\section{O CHAVISMO IMPLANTOU O SOCIALISMO NA VENEZUELA? UM ESTUDO DE CASO SOBRE COMO CONCEITUAR ECONOMIAS CONTEMPORÂNEAS}

\section{LUCAS LEMOS WALMRATH \\ WALLACE DE MORAES}

FERMIN, Eudis; SOTELDO, Juan P. El socialismo bolivariano en Venezuela: construcción de un modelo de desarrollo socio-económico. Universitas: Relações Internacionais, v. 12, n. 1, 22 jul. 2014. Disponível em: $<$ https://www.publicacoesacademicas.uniceub.br/relacoesinternacionais/article/view/2602>. Acesso em: 9 jan. 2019.

FOX NEWS. ASSOCIATED PRESS. What socialism? Private sector still dominates Venezuelan economy despite Chavez crusade. Disponível em: $<$ http://www.foxnews.com/world/2010/07/18/socialism-private-sector-dominates-venezuelaneconomy-despite-chavez-crusade.html>. Acesso em: 21 abr. 2018.

FUKUYAMA, Francis. The End of History and the Last Man. 1a ed. New York: Free Press, 2006 [1992].

HAWKINS, Kirk. Populism in Venezuela: the rise of Chavismo. Third World Quarterly, v. 24, n. 6, p. 1137-1160, dez. 2003.

How Chávez and Maduro have impoverished Venezuela. The Economist, 6 abr. 2017. Disponível em: <https:/www.economist.com/news/finance-and-economics/21720289-overpast-year-74-venezuelans-lost-average-87kg-weight-how>. Acesso em: 21 abr. 2018.

KATZ, Claudio. Las encrucijadas del nacionalismo radical. La página de Claudio Katz. [S.1: s.n.]. Disponível em: <https://www.lahaine.org/b2-img/katzencr.pdf>. Acesso em: 21 abr. 2018. 20 nov. 2007.

KROPOTKIN, Piotr. A conquista do pão. Lisboa: Guimarães Editores, 1975.

LANDER, Luis E. "Petróleo e democracia na Venezuela: do fortalecimento do Estado à sublevação soterrada e à insurreição aberta". In OURIQUES, Nildo (org.) Raízes no Libertador. Boliavarianismo e poder popular na Venezuela. Florianópolis: Insular, 2005.

LANZARO, Jorge. La Tercera Ola de las Izquierdas Latinoamericanas: Entre el Populismo y la Social Democracia. Manuscrito, 2006.

LÓPEZ MAYA, Margarita. (2006). "Venezuela 2001-2004: actores y estratégias en la lucha hegemônica". In: CAETANO, Gerardo. Sujetos sociales y nuevas formas de protesta em la historia reciente de América Latina. Buenos Aires: Conselho Latinoamericano de Ciências Sociales - CLACSO.

; SMILDE, David; STEPHANY, Keta. (2003) "La protesta popular venezolana entonces y ahora: ?câmbios em la política de la calle?" Revista Politeia, 30: 157-181. Instituto de Estúdios Políticos, Universidad Central de Venezuela.

LOWRY, Rich. Venezuela: a nation devoured by socialism. New York Post. Disponível em: $<$ https://nypost.com/2017/08/01/venezuela-a-nation-devoured-by-socialism/>. Acesso em: 21 abr. 2018. 1 ago. 2017 


\section{O CHAVISMO IMPLANTOU O SOCIALISMO NA VENEZUELA? UM ESTUDO DE CASO SOBRE COMO CONCEITUAR ECONOMIAS CONTEMPORÂNEAS}

\section{LUCAS LEMOS WALMRATH \\ WALLACE DE MORAES}

MAINWARING, Scott. From Representative Democracy to Participatory Competitive Authoritarianism: Hugo Chávez and Venezuelan Politics. Perspectives on Politics, v. 10, n. 04, p. $955-967$, dez. 2012.

MARX, Karl; ENGELS, Friedrich. Manifesto do partido comunista. Edição: $1^{\mathrm{a}}$ ed. [S.1.]: Penguin, 2012.

MBAH, Sam; IGARIWEY, I.E (2001) African Anarchism: the history of movement. Disponível em: https://libcom.org/history/sam-mbah-i-e-igariwey

MITCHELL, Jason. Venezuela is collapsing into socialist induced chaos, yet it remains a Corbynista poster child. The Telegraph, 1 maio 2017. Disponível em: $<$ https://www.telegraph.co.uk/news/2017/05/01/venezuela-collapsing-socialist-inducedchaos-yet-remains-corbynista/>. Acesso em: 21 abr. 2018.

MORAES, Wallace De. Governados por quem? Diferentes plutocracias nas histórias políticas de Brasil e Venezuela. 2a ed. Rio de Janeiro: Ape'ku, 2019.

NETTLAU, Max. História da anarquia: das origens ao anarco-comunismo. São Paulo: Hedra, 2008 .

Novíssimo dicionário de economia. $3^{\text {a }}$ ed. São Paulo: Editora Best Seller, 1999

PANNIZZA, Francisco (ed.). Populism and the Mirror of Democracy. Londres: Verso, 2005.

PARTIDO SOCIALISTA UNIDO DE VENEZUELA - PSUV. Chávez asumió hace nueve años como presidente reelecto encaminado al socialismo del siglo XXI. institucional. Disponível em: <https://www.psuv.org.ve/temas/noticias/hugo-chavez-venezuela-presidentereeleccion-socialismo-siglo-xxi/\#.W4GxHc5Kjcc>. Acesso em: 9 jan. 2019.

PETKOFF, Teodoro. (2007) “As Duas Esquerdas”. Nueva Sociedad, www.nuso.org.

PETRAS, James. (2007) "Día-D para Venezuela". El 2, de diciembre, referéndum constituyente. Artigo original: http://petras.lahaine.org/articulo.php?p=1717.

PROUDHON, Pierre-Joseph (2001). A propriedade é um roubo e outros escritos anarquistas: seleção e notas de Daniel Guérin. Porto Alegre: L\&PM.

RODRIK, Dani. Goodbye Washington Consensus, Hello Washington Confusion? A Review of the World Bank's Economic Growth in the 1990s: Learning from a Decade of Reform. Journal of Economic Literature, v. 44, n. 4, p. 973-987, dez. 2006.

Routledge Dictionary of Economics. 2a ed. Londres e Nova Iorque: Routledge, 2002

SCHAMIS, Hector E. Populism, Socialism, and Democratic Institutions. Journal of Democracy, v. 17, n. 4, p. 20-34, 2006. 


\section{O CHAVISMO IMPLANTOU O SOCIALISMO NA VENEZUELA? UM ESTUDO DE CASO SOBRE COMO CONCEITUAR ECONOMIAS CONTEMPORÂNEAS}

\section{LUCAS LEMOS WALMRATH \\ WALLACE DE MORAES}

SEABRA, Raphael Lana. A primeira revolução do século XXI? : bolivarianismo e socialismo Venezuela. 2012. 237 f. Tese de Doutorado - UnB, Brasília, 2012. Disponível em: $<$ http://repositorio.unb.br/handle/10482/10635>. Acesso em: 10 jan. 2019.

SHEAHAN, John. Alternative models of capitalism in Latin America. In HUBER, Evelyne (ed.). Models of Capitalism: Lessons from Latin America. Pennsylvania, University Park, 2002.

SOARES, Eliane. Revolução nacional-democrática e socialismo na américa latina: As Experiências da Revolução Bolivariana da Venezuela e da Revolução Cubana de 1959. Revista de Estudos e Pesquisas sobre as Américas, v. 4, n. 1, 2 jul. 2010. Disponível em: $<$ http://periodicos.unb.br/index.php/repam/article/view/16097>. Acesso em: 11 jan. 2019.

The Concise Oxford Dictionary of Politics. [S.1.]: Oxford University Press, 2009.

The MIT Dictionary of Modern Economics. 4a ed. Grã-Bretanha: MIT Press, 1992.

The Routledge Dictionary of Politics. [S.1.]: Routledge, 2004

THE WORLD BANK. The World Bank In Venezuela. Disponível em: $<$ http://www.worldbank.org/en/country/venezuela/overview>. 2017. Acesso em: 21 abr. 2018.

UZCÁTEGUI, Rafael. (2010) Venezuela: La Revolución como espetáculo. Una crítica anarquista al gobierno bolivariano. Caracas, Madri, Tenerife, Buenos Aires: El libertário/ Editorial La Cucaracha Ilustrada/ La Malatesta Editorial/ Tierra de Fuego/ Libros de Anarres.

WEISBROT, Mark; SANDOVAL, Luis. The Venezuelan Economy in the Chávez Years. Washington, DC: Center for Economic and Policy Research (CEPR), jul. 2007. Disponível em: <http://cepr.net/documents/publications/venezuela_2007_07.pdf >. Acesso em: 3 out. 2018.

WOODCOCK, George (2002) História das ideais e do movimento anarquista. Vol. 1. Porto Alegre: L\&PM.

ZELIK, Raúl. "Socialismo del siglo XXI" o viejo centrismo estatal? Una lectura disidente de las transformaciones en Venezuela. Forum. Revista Departamento Ciencia Política, v. 1, n. 1, p. 13-34, 1 jan. 2011. 